\title{
Freedom and happiness in nations: why the Finns are happier than the French
}

Gaël Brulé ${ }^{1,2^{*}}$ and Ruut Veenhoven ${ }^{1,3}$

\footnotetext{
* Correspondence: brule@ese.eur.nl ${ }^{1}$ Erasmus University Rotterdam, Rotterdam, Netherlands

${ }^{2}$ Erasmus Happiness Economics Research Organization, POB 1738, NL3000DR Rotterdam, Netherlands Full list of author information is available at the end of the article
}

\begin{abstract}
Cross-national studies on happiness have revealed large differences, not only is average happiness higher in rich nations than in poor ones, but there are also sizable differences in happiness among rich nations. For instance, the Finns are happier than the French, while GDP per capita is similar in France and Finland. In this paper we discuss whether freedom can explain that difference. The Finns feel more free than the French do. Does this discrepancy in perceived freedom correspond to a difference in actual freedom? Following Bay, we distinguished three kinds of actual freedom: social freedom, potential freedom and psychological freedom. In a comparative analysis of 49 nations we find that actual freedom reflects only partially in perceived freedom and that all kinds of freedom have some independent relation with average happiness. Psychological freedom is most strongly related to happiness in rich nations. The Finns are happier than the French because they dare more to be free.

Keywords: Happiness; Life satisfaction; Freedom; Perceived freedom; Social freedom; Psychological freedom; Potential freedom; Path analysis
\end{abstract}

\section{Introduction}

Comparative research on happiness shows, typically, that people live happiest in the richest nations of this world. This pattern was already visible in the first cross national in 1960 by Cantril (1965) and has been replicated over and again on ever larger numbers of nations. A plot of happiness versus buying power in 138 countries in 2005 is presented in Figure 1. Happiness here is defined as life satisfaction as further explained in part 2.

\section{Average happiness differs across rich nations}

Happiness increases significantly with GDP in the first part of the graph, where the poor nations are situated, and reach a plateau around 18,000 dollars per capita. In these nations, sufficient individuals have a purchasing power high enough for economic affluence to have little influence on happiness; this represents 49 nations ${ }^{\text {a }}$. Among the rich nations, we see large differences in happiness among countries with the same purchasing power, e.g. more than two points between Hong Kong and Denmark, one point and a half between France and Finland.

\section{Comparison between Finland and France}

Let us consider this latter case in more detail. Finland and France are both affluent societies, with purchasing powers per capita that are very comparable $(\$ 32,153$ for Finland

(c) 2014 Brulé and Veenhoven; licensee Springer. This is an Open Access article distributed under the terms of the Creative Commons Attribution License (http://creativecommons.org/licenses/by/4.0), which permits unrestricted use, distribution, and reproduction in any medium, provided the original work is properly credited. 


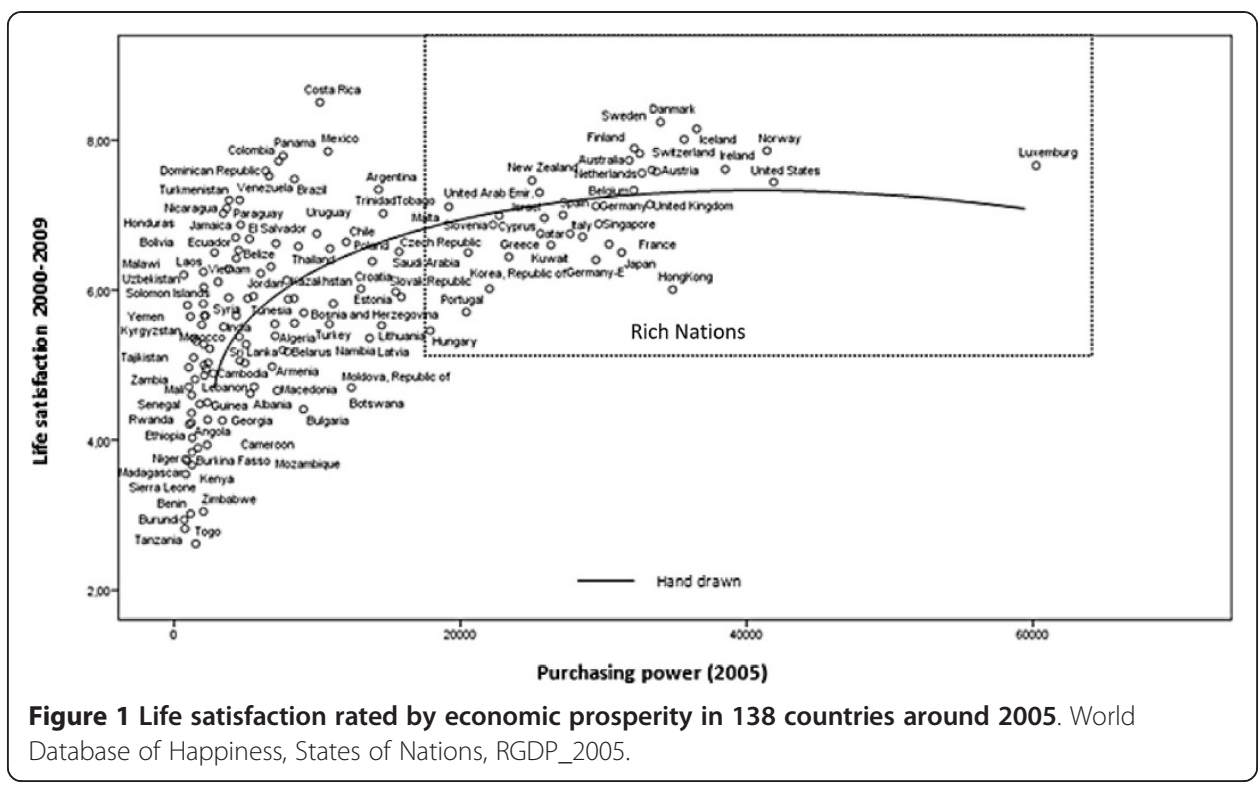

versus $\$ 30,386$ for France in 2005), yet with remarkable life satisfaction differences, as shown in Table 1. The difference in happiness is consistent: the French are not only less satisfied with their lives as a whole, they also feel less well affectively and see a greater difference between how their lives are and how they want it to be compared to the Finns. In short, this case represents one of the cases where two countries from the same civilization (western culture), with similar purchasing powers, present the highest difference in happiness.

This example illustrates that there can be large differences in happiness and its components at comparable economic development. So happiness depends on more than just wealth. What other factors can be involved? We considered other factors, widely regarded as the most important societal predictors for happiness, to be: quality of government, rule of law, social security, and inequality in income and between sexes (Ott 2010). Finland has a substantial advantage on government effectiveness and rule of law, a slight advantage in terms of sex inequality, both countries were comparable in terms of income inequality, while France was ahead in terms of social security. We saw differences in these factors, mostly in favour of Finland, but no difference seemed significant enough to explain this 'happiness gap'. Results are summarized in Table 2 below.

Table 1 Average happinesses in France and Finland for the period 2000-2009

\begin{tabular}{llll}
\hline Nation & $\begin{array}{l}\text { Life satisfaction } \\
\text { (Overall } \\
\text { happiness) }\end{array}$ & $\begin{array}{l}\text { Mood } \\
\text { (Affective } \\
\text { component) }\end{array}$ & $\begin{array}{l}\text { Contentment } \\
\text { (Cognitive } \\
\text { component) }\end{array}$ \\
\hline Finland & 7.9 & 54 & 7.6 \\
France & 6.6 & 42 & 7.0 \\
Average rich countries & 7.0 & 45 & 6.7 \\
Difference & & & 0.6 \\
- in points on scale & 1.3 & 12 & $12 \%$ \\
-in \% actual scale range in the world & $26 \%$ & $25 \%$ & $21 \%$ \\
$-n$ \% actual range among the rich nations & $40 \%$ & $30 \%$ & \\
\hline
\end{tabular}


Table 2 Institutional differences between France and Finland

\begin{tabular}{lllll}
\hline Factor & $\begin{array}{l}\text { Reference in data file } \\
\text { 'States of Nations' }\end{array}$ & Finland & France & $\begin{array}{l}\text { Percentage of the total } \\
\text { range of rich countries }\end{array}$ \\
\hline Government effectiveness $^{3}$ & GovEffectiveness_2006 & 2.2 & 1.5 & $30 \%$ \\
Rule of law $^{4}$ & RuleLaw_2006 & 2.0 & 1.4 & $22 \%$ \\
Social security $^{5}$ & WelfareExpense1_2006 & 26 & 29 & $13 \%$ \\
Income Inequality $^{6}$ & Incomeequality_2000_2008 & 33 & 30 & $12 \%$ \\
& Incomelnequality1_2006 & 27 & 33 & $24 \%$ \\
Gender Inequality $^{7}$ & GenderEquality_2_2005 & 0.89 & 0.72 & $25 \%$ \\
& GenderEquality_4_2007 & 0.95 & 0.95 & $0 \%$ \\
\hline
\end{tabular}

${ }^{2}$ This percentage represents the ratio (difference between France and Finland)/highest difference amongst rich nations ${ }^{3}$ Veenhoven (2014b) States of Nations, Governance, Erasmus University of Rottodam, accessed on 1/11/2011 Available at: worlddatabaseofhappiness.eur.nl/statnat/statnat_fp.htm.

${ }^{4}$ Veenhoven (2014b)) States of Nations, Law and order, Legal system, Erasmus University of Rottodam, accessed on 1/11/2011 Available at: worlddatabaseofhappiness.eur.nl/statnat/statnat_fp.htm.

${ }^{5}$ Veenhoven (2014b) States of Nations, Health, health expenditures, Erasmus University of Rottodam, accessed on 1/11/2011

Available at: worlddatabaseofhappiness.eur.nl/statnat/statnat_fp.htm.

${ }^{6}$ Veenhoven (2014b) States of Nations, inequality, income inequality, Erasmus University of Rottodam, accessed on 1/11/2011 Available at: worlddatabaseofhappiness.eur.nl/statnat/statnat_fp.htm.

${ }^{7}$ Veenhoven (2014b) States of Nations, inequality, gender inequality, Erasmus University of Rottodam, accessed on 1/11/2011 Available at: worlddatabaseofhappiness.eur.nl/statnat/statnat_fp.htm.

\section{Focus on freedom}

What are the other factors that might be involved here? According to Verme (2009), a sense of freedom is the strongest predictor for happiness across nations. There are indeed sizable differences in perceived freedom among rich nations and the French feel less free than the Finns do (6.2 versus 7.5 on a ten-scale) ; however, one needs to be careful as this correlation might be inflated by a common response tendency, i.e. a tendency to answer less positively to any question. If no such distortion of responses is at hand, it is still possible that this difference in perceived freedom does not correspond with a difference in actual freedom. The French could be more perceptible for limitations to freedom than the Fins are, while they are in fact equally free is also possible that the difference is largely driven by happiness, unhappiness making people more prone to see their limitations than their opportunities. Thus we decided to investigate the freedom factor in greater depth.

\section{Plan of this paper}

We start by explaining what we mean by 'happiness' and next discuss the concept of freedom. Following Bay we distinguish several kinds of actual freedom and note the difference with perceived freedom. Next we analyze the relationship between these freedom variants and average happiness in 49 wealthy nations. We will then show that actual freedom, affects happiness, both directly and indirectly through perceived freedom. The difference between Finland and France fits that wider pattern.

\section{Concepts and measures}

The terms 'happiness' and 'freedom' are often used in political rhetoric, but are in that context seldom properly defined. Greater precision is required for this empirical analysis, both with respect to the concepts and for their measurement.

\subsection{Happiness}

What is 'happiness' precisely? How can we measure happiness in nations? 


\subsubsection{Concept}

The word 'happiness' is used in a number of ways. In this paper the word is used to denote a sense of satisfaction with life. Following Veenhoven (1984) we define happiness as the degree to which someone evaluates the overall quality of his or her present life-as-a-whole positively. In other words, how much a person likes the life he or she lives.

When asked to appraise how much we like our life, we draw on two sources of information: how well we feel generally and how well our life-as-it-is meets our standards of how-lifeshould-be. These sub-appraisals are referred to as the 'affective' and 'cognitive' components of happiness, and called respectively 'hedonic level of affect' and 'contentment' (Veenhoven, 2009). In this paper we consider both overall happiness and these two components.

\subsubsection{Measures of happiness in nations}

Thus defined, happiness is something we have in mind, and things that are on our mind can be assessed using questioning. Questions designed to determine individuals happiness can be framed in many ways, both directly or indirectly, and using single or multiple questions. An overview of acceptable questions is available in the collection 'Measures of Happiness' part of the World Database of Happiness (Veenhoven, 2014c). Answers to the following frequently used questions on happiness provided the input data for the analysis presented in this paper.

Overall happiness A commonly used survey question on happiness is: 'Taking all together, how satisfied or dissatisfied are you with your life as a whole these days?', Please answer by ticking a number between 0 to 10 , where 0 stands for most 'dissatisfied' and 10 for most 'satisfied". Responses to this question and equivalent questions are gathered in the collection 'Happiness in Nations' of the World Database of Happiness (Veenhoven 2014d). Together this yields comparable data on average happiness in 150 nations over the years 2000 to 2009, which are included in the data file 'States of nations' variable HappinessLS10.11_2000s in the data file 'States of Nations' (Veenhoven, 2014b), which was used for this study.

Affect level The affective component of happiness is measured on the basis of responses to a series of questions as to how the respondent had felt the day before the questionnaire was administrated. This measure was used in the Gallup World Polls (Gallup, 2009). Typical questions are whether one had felt 'depressed,' 'stressed' or had felt 'well rested' and 'smiled a lot' yesterday. Respondents could answer 'yes' or 'no'. We computed an affect balance score per nation, subtracting the percentage of reported negative feelings from the percentage of positive feelings. The variable name in the data file States of Nations is HappinessYesterdayABS_2006.08.

Contentment The cognitive component of happiness is measured using the Cantril ladder (Cantril, 1965). In this case the respondent is presented with a picture of a ladder and then asked: 'Suppose the top of the ladder represents the best possible life for you and the bottom of the ladder the worst possible life. Where on this ladder do you feel you personally stand at the present time?'. Answers are rated on a 11-step scale ranging from 0 to 10. The variable label in data file States of Nations is: HappinessBW11_2006. 


\subsection{Freedom}

What is 'freedom' precisely? How can that be measured in nations? Is there a difference between 'actual' freedom and 'perceived freedom in nations?

\subsubsection{Concepts}

In the broadest sense, freedom can be defined as the possibility for an individual to make choices, typically major life choices. The 'possibility' to choose requires first of all that there is an 'opportunity' to choose, which is an attribute of the environment in which an individual lives. Then, making a choice requires that an individual has the 'capacity' to choose, which is an individual attribute (Veenhoven 2000).

Following Bay (1970) we further distinguish two aspects of the capacity to choose, which results in three kinds of freedom: social freedom, psychological freedom and potential freedom. Social freedom is about opportunity to choose and denotes absence of restriction by other people. Psychological freedom is about the capacity to choose and denotes absence of inner restrictions. Potential freedom is about information on possible choice options and awareness of external opportunities.

This difference in three kinds of freedom can be illustrated by the case of a prisoner in a cell with an unlocked door and a route to freedom. The prisoner can decide not to use that opportunity to escape because he or she foresees punishment. This is a case of social unfreedom. The prisoner can also decide to forego the escape opportunity because he or she does not dare to escape, preferring the security of the prison above the challenges of real life. This is a case of psychological unfreedom. Lastly the prisoner can miss out the escape opportunity because he or she did not know that the door was open. This is a case of potential unfreedom. In addition to actual freedom, there is perceived freedom. Though typically related, these kinds of freedom can diverge; one can think one is free while one is not, or think one is not free in spite of considerable choice. Both actual freedom and perceived freedom can affect happiness, possibly independently.

\subsubsection{Indicators of freedom in nations}

How can these three kinds of freedom be measured and compared across nations?

Actual freedom Below we present the available indicators for the three kinds of actual freedom in nations and check whether the conceptual distinction is reflected in the data. Full detail is presented on the technical appendix Table 3.

Social freedom External restriction to choice can be measured in different domains. In this study we use available information on choice restrictions in the domains of economic life, political life and private life of citizens (or individuals within that nation).

- Economic freedom is measured by absence of restrictions on business using available indexes that differ slightly in the aspects they cover. We combined three indexes to get an average "Economic freedom" index: the Economic Freedom of the World, the Heritage Index and the Freedom House Index. Indexes are detailed in Table 2.

- Political freedom is measured using absence of restrictions for individuals to participate in the political process, such as civil liberties within a nation. Nation scores on these matters 
Table 3 Variables used in comparative analysis of 49 nations

\begin{tabular}{|c|c|c|}
\hline Variable & Measurement & Name in data file States of nations \\
\hline Happiness & $\begin{array}{l}\text { Average answer to question Taking all together, how } \\
\text { satisfied or dissatisfied are you with your life as a whole } \\
\text { these days?' }\end{array}$ & HappinessLS10.11-2000 s ${ }^{10}$ \\
\hline Contentment & $\begin{array}{l}\text { Average answer to question 'Here is a picture of a } \\
\text { ladder, suppose that the top represents the best } \\
\text { possible life and the bottom the worst possible life. } \\
\text { Where on this ladder would you place your current } \\
\text { life?' }\end{array}$ & HappinessBW11_11to15aged_2001.2006 ${ }^{11}$ \\
\hline $\begin{array}{l}\text { Hedonic level } \\
\text { of affect }\end{array}$ & $\begin{array}{l}\text { The affective component of happiness is measured on } \\
\text { the basis of responses to a series of } 14 \text { questions on } \\
\text { how one has felt yesterday, which figured in the Gallup } \\
\text { World Polls (Gallup, 2009). Typical questions are } \\
\text { whether one had felt 'depressed', 'stressed' or rather } \\
\text { had felt 'well rested' and 'smiled a lot' yesterday. } \\
\text { Respondents could answer 'yes' or 'no'. We computed } \\
\text { an affect balance score per nation, subtracting the } \\
\text { percentage of negative feelings from the percentage } \\
\text { of positive feelings. The variable name in the data file } \\
\text { States of Nations is HappinessYesterdayABS_2006.08. }\end{array}$ & HappinessYesterdayABS_2006.08 $8^{12}$ \\
\hline \multirow[t]{2}{*}{$\begin{array}{l}\text { Psychological } \\
\text { freedom }\end{array}$} & $\begin{array}{l}\text { Rosenberg (1965) Self Esteem Scale: 10-item } \\
\text { questionnairea: I feel that I am a person of worth, at } \\
\text { least on an equal plane with others, b: I feel that I have } \\
\text { a number of good qualities, c: All in all, I am inclined to } \\
\text { feel that I am a failure, d: I am able to do things as well } \\
\text { as most other people, e: I feel I do not have much to } \\
\text { be proud of, f: I take a positive attitude toward myself, } \\
\text { g: On the whole, I am satisfied with myself, h: I wish I } \\
\text { could have more respect for myself, i: I certainly feel } \\
\text { useless at times, j: At times I think I am no good at all }\end{array}$ & SelfEsteem_2002 $2^{13}$ \\
\hline & Acquiescence: Revised NEO personality inventory & Acquiescence_2002 $2^{14}$ \\
\hline $\begin{array}{l}\text { Political } \\
\text { freedom }\end{array}$ & $\begin{array}{l}\text { Civil liberties: respect of civil liberties in nations is } \\
\text { estimated on the basis of expert rating of eleven } \\
\text { aspects: } 1 \text {. Free and independent media, 2. Open } \\
\text { public discussion, free private discussion, 3. Freedom of } \\
\text { assembly and demonstration, 4. Freedom of political } \\
\text { organization, } 5 \text {. Equal law, non-discriminatory judiciary, } \\
6 \text {. Protection from political terror, 7. Free trade unions, } \\
\text { effective collective bargaining, 8. Free professional and } \\
\text { other private organizations, 9. Free business, 10. Free } \\
\text { religion, } 11 \text {. Personal freedoms such as: gender equality, } \\
\text { property rights, freedom of movement, choice of } \\
\text { residence, choice of marriage and size of family. Score } \\
\text { are also available for } 132 \text { nations. Scores are given } \\
\text { between } 1 \text { and } 7 \text { by a team of regional experts and } \\
\text { scholars (A rating of } 1 \text { indicates the highest degree of } \\
\text { freedom and } 7 \text { the least amount of freedom) }\end{array}$ & CivilLiberties_2004 $^{15}$ \\
\hline $\begin{array}{l}\text { Private } \\
\text { freedom }\end{array}$ & $\begin{array}{l}\text { 1) Abortion: (FreeAbortion_1995): Legal grounds, } \\
\text { number in law. Grounds are: a) to save women's life, b) } \\
\text { to preserve physical health, c) to preserve mental } \\
\text { health, d) rape or incest, e) foetal impairment, f) } \\
\text { economic or social reasons, g) on request. Higher } \\
\text { number indicates more freedom.2) Marriage } \\
\text { (FreeMarriage_1990, 'Legal restrictions to interracial, } \\
\text { interreligious, or civil marriage' and 'Equality of sexes } \\
\text { during marriage and for divorce proceedings'), as } \\
\text { ranked by Humana (1992) on a scale from } 1 \text { to 4, items } \\
36 \text { and 373) Travel (mean of FreeTravel1_1990 } \\
\text { 'Freedom to travel in own country' and } \\
\text { FreeTravel2_1990 'freedom to travel outside the } \\
\text { country') as ranked by Humana (1992) on a scale from } \\
1 \text { to } 4(\text { (items } 1 \text { and 2), }\end{array}$ & PrivateFreedom_1990s ${ }^{16}$ \\
\hline $\begin{array}{l}\text { Economic } \\
\text { freedom }\end{array}$ & $\begin{array}{l}\text { Economic freedom Index 1: The first index of } \\
\text { Economic Freedom of the World (EFW) was compiled } \\
\text { by Gwartney and Lawson (2006) and is called the }\end{array}$ & FreeEconlndex1_2006 ${ }^{17}$ \\
\hline
\end{tabular}


Table 3 Variables used in comparative analysis of 49 nations (Continued)

\begin{tabular}{|c|c|c|}
\hline & $\begin{array}{l}\text { Fraser Index. The EFW index contains } 38 \text { components } \\
\text { designed to measure the degree to which a nation's } \\
\text { institutions and policies are consistent with voluntary } \\
\text { exchange, protection of property rights, open markets, } \\
\text { and minimal regulation of economic activity. The } \\
\text { indexes are classified in } 5 \text { categories: size of the } \\
\text { government, property rights, access to sound money, } \\
\text { freedom to trade internationally, regulation of credit } \\
\text { labour and business. Scores on this index are available } \\
\text { for } 138 \text { nations around } 2006 \text {. }\end{array}$ & \\
\hline & $\begin{array}{l}\text { Economic freedom Index 2: Freedom House Index } \\
\text { developed by (Messick and Kimura, 1996): A total of } \\
\text { eighty-two countries are rated using six criteria: } \\
\text { Freedom to hold property, Freedom to earn a living, } \\
\text { Freedom to operate a business, Freedom to invest } \\
\text { one's earnings, Freedom to trade internationally, and } \\
\text { Freedom to participate in the market economy. For the } \\
\text { first four items, countries are scored 0, 1, 2, or 3, with } 3 \\
\text { being the most free. For the last two items, countries } \\
\text { are scored 0, 1, or 2, with two being the most free. } \\
\text { The index is based on the simple sum of these six } \\
\text { scores. The highest possible score, indicating the most } \\
\text { freedom, is 16. The lowest possible score is 0. Scores } \\
\text { on this index are available for } 69 \text { nations in the years } \\
\text { 1995-96. }\end{array}$ & FreeEconIndex3_1995 \\
\hline \multirow[t]{2}{*}{$\begin{array}{l}\text { Potential } \\
\text { Freedom }\end{array}$} & $\begin{array}{l}\text { Internet Use: Availability of internet users per } 1000 \\
\text { people as defined by the United Nations-United } \\
\text { Development Reports (2007)-table thirteen }\end{array}$ & InternetUse_2005 ${ }^{19}$ \\
\hline & $\begin{array}{l}\text { Newspaper Use: Newspaper consumption per } 1000 \\
\text { people as defined by the United Nations-United } \\
\text { Development Reports (1998)-table thirty four }\end{array}$ & Newspapers_199520 \\
\hline
\end{tabular}

Veenhoven (2014b) States of Nations, Happiness, Average happiness, Erasmus University of Rottodam, accessed on 1/11/2011.

${ }^{11}$ Veenhoven (2014b) States of Nations, Happiness, Average happiness, Erasmus University of Rottodam, accessed on 1/11/2011.

${ }^{12}$ Veenhoven (2014b) States of Nations, Happiness, Average happiness, Erasmus University of Rottodam, accessed on 1/11/2011.

${ }^{13}$ Veenhoven (2014b) States of Nations, Personality, Erasmus University of Rottodam, accessed on 1/11/2011.

${ }^{14}$ Veenhoven (2014b) States of Nations, Personality, Erasmus University of Rottodam, accessed on 1/11/2011.

${ }^{15}$ Veenhoven (2014b) States of Nations, Freedom, Democracy, Erasmus University of Rottodam, accessed on 1/11/2011.

${ }^{16}$ Veenhoven (2014b) States of Nations, Freedom, Private Freedom, Erasmus University of Rottodam, accessed on 1/11/2011.

${ }^{17}$ Veenhoven (2014b) States of Nations, Freedom, Economic Freedom,Erasmus University of Rottodam, accessed on 1/11/2011.

${ }^{18}$ Veenhoven (2014b) States of Nations, Freedom, Economic Freedom,Erasmus University of Rottodam, accessed on 1/11/2011.

${ }^{19}$ Veenhoven (2014b) States of Nations, Modernity, Informatization, Erasmus University of Rottodam, accessed on 1/11/2011.

${ }^{20}$ Veenhoven (2014b) States of Nations, Modernity, Informatization, Erasmus University of Rottodam, accessed on 1/11/2011.

are gathered by Freedom House F (2005). Indexes for civil liberties are presented in Table 2.

- Private freedom is measured absence of restrictions on choice in the personal sphere of life, such as travel, abortion and marriage, first gathered by Veenhoven (2000).

Data on the above mentioned indicators of social freedom were taken from the dataset 'States of Nations (Veenhoven 2014b) On that basis we calculated a comprehensive index of social freedom by adding the $\mathrm{z}$ scores of the indexes of economic freedom, private freedom and political freedom above and then the indicator was adjusted to a [0-1] range.

Psychological freedom Psychological freedom is a lack of inner restrictions for seizing opportunities to choose. There are several such inhibitions and we do have data on the prevalence of some of the inhibitions in nations.

- A first inner constraint is low self esteem. If you do not feel good about yourself, you will be less apt to take control. Self esteem is commonly measured using the Rosenberg Self- 
Esteem Scale (Rosenberg, 1965) and average scores on that scale are available for 53 nations over the years 1965-2002 (Schmitt \& Allik, 2005). The variable name is SelfEsteem_2002.

- A second psychological restraint is acquiescence, that is, a tendency to agree with what other people say. This trait is measured using 'yes-saying' to survey questions and is commonly used as an indicator of response style. However, a strong tendency to agree to any question can also be seen as a 'lack of guts', i.e. a lack of psychological freedom. Data is available for 56 nations over the years 1980-2004 (Smith, 2004). The variable name in States of Nations is Acquiescence_2002.

We calculated a comprehensive index of psychological freedom by adding the $\mathrm{z}$ scores of the two aspects, giving positive weight to self esteem and negative weight to acquiescence. The indicator was then adjusted to a [0-1] range.

Potential freedom As noted above, potential freedom is one's awareness of opportunities. As such potential freedom in nations may be reflected by two indicators:

- the number of newspapers per 1000 inhabitants

- access to internet.

The indicator for potential freedom was calculated as the sum of these adjusted to a [0-1] range.

Total actual freedom Finally, the indicator of actual freedom was calculated as the sum of social freedom, psychological freedom and potential freedom, adjusted to a [0-1] range.

Relationship between the three types of freedom in nations We conducted a factor analysis in order to see how the different indicators presented above were connected to the three indices following Bay (1970) classification. The results are presented in Table 4 below. We conducted first a factor analysis to determine the number of factors. Using the scree plot, three factors had an Eigen value superior than 1 and the slope was sharper after the third factor; this confirmed the prominence of three factors. The variance explained by these three factors is $76.3 \%$. After a varimax rotation, we obtain the factor loadings shown in Table 5, values below 0.30 are not considered. Three factors load distinctively. Nonetheless, there are some overlaps between the different types of freedom; freedom to travel loads mainly on social freedom, but there is a small loading on factor 2, psychological freedom. Economic freedom 2 loads almost as much on factor 3, potential freedom as on factor 1, social freedom. Finally, the number of newspaper is loading mainly on potential freedom as expected, but it loads almost as much negatively on factor 2, psychological freedom.

Still the three factors reflect Bay's taxonomy fairly well.

Perceived freedom Perceived freedom in nations is the degree to which citizens feel they are in control of their life. The World Values Surveys contain a question on that matter that reads 'Some people feel they have completely free choice and control over their lives, while other people feel that what they do has no real effect on what happens to them. Please use 
Table 4 Indicators of freedom in nations: a factor analysis $(\mathbf{N}=33)$

\begin{tabular}{llll}
\hline & $\begin{array}{l}\text { Social Freedom } \\
\text { Factor } \mathbf{1}\end{array}$ & $\begin{array}{l}\text { Psychological freedom } \\
\text { Factor } \mathbf{2}\end{array}$ & $\begin{array}{l}\text { Potential freedom } \\
\text { Factor3 }\end{array}$ \\
\hline Freedom of marriage & $\mathbf{. 9 6 5}$ & & \\
Freedom to travel &. $\mathbf{8 9 3}$ & -.321 & \\
Freedom to abort &. $\mathbf{3 6 9}$ & & \\
Suppression Civil Liberties & $\mathbf{- . 9 3 8}$ & & \\
Economic freedom 1 & .700 & & .515 \\
Economic freedom 2 & $\mathbf{. 5 8 1}$ & $-\mathbf{0 . 9 8 8}$ & \\
Acquiescence & & $\mathbf{0 . 5 7 5}$ & $\mathbf{. 9 1 1}$ \\
Self-esteem & & -.590 & $\mathbf{6 1 5}$ \\
Internet users & & & \\
Number of newspaper & &
\end{tabular}

The highest values for each factor are represented in bold.

this scale where 1 means "none at all" and 10 means "a great deal" to indicate how much freedom of choice and control you feel you have over the way your life turns out'. This variable is available for 85 nations between 1990 and 2005 and is labelled as FreeLife_1990.2005 in the data file States of Nations.

\section{Results}

Let us now see how freedom and happiness relate in rich nations. Note that we do not report statistical significance of correlations; since our data cover almost all developed nations such test makes no sense.

\subsection{Actual and perceived freedom}

As shown in Table 5, the zero-order correlations of social, potential and psychological freedom with perceived freedom are equivalent (respectively $+.32,+.29$ and +.32 ) but small One interpretation is that our measures of actual freedom do not capture the limitations to choice very well. Another interpretation is that much of the perceived freedom is illusory.

\subsection{Happiness and actual freedom}

All correlations between happiness and freedom in Table 6 are positive, which means that freedom and happiness tend to go hand in hand. The zero-order correlations vary from modest in the case of psychological freedom $(r=+.27)$ to strong in the case of potential freedom $(\mathrm{r}=+.60)$. The pattern changes dramatically when controlling for economic prosperity. Whereas the partial correlation of psychological freedom with happiness increases slightly from +.27 to +30 , the correlations with social and potential freedom are largely wiped out. This means that the latter two kinds of freedom are a by-product of societal development, while psychological freedom is rather independent or even negatively

Table 5 Zero order correlations between perceived freedom and actual freedom indicators $(\mathrm{N}=\mathbf{3 3})$

\begin{tabular}{lllll}
\hline & $\begin{array}{l}\text { 1.Perceived } \\
\text { freedom }\end{array}$ & $\begin{array}{l}\text { 2.Social } \\
\text { freedom }\end{array}$ & $\begin{array}{l}\text { 3.Psychological } \\
\text { freedom }\end{array}$ & $\begin{array}{l}\text { 4.Potential } \\
\text { freedom }\end{array}$ \\
\hline 1.Perceived freedom & - & +.32 & +.32 & +.29 \\
2.Social freedom & - & - & -.16 & +.42 \\
3.Psychological freedom & - & - & - & +.42 \\
\hline
\end{tabular}


Table 6 Freedom and happiness in 33 nations 2000-2009

\begin{tabular}{lll}
\hline Freedom & \multicolumn{2}{l}{ Correlation with average happiness } \\
\cline { 2 - 3 } & zero-order & wealth controlled \\
\hline Actual freedom & +.37 & +.09 \\
- social freedom & +.27 & +.30 \\
- psychological freedom & +.60 & +.11 \\
- potential freedom & +.64 & +.48 \\
Perceived freedom & & \\
\hline
\end{tabular}

correlated to societal development. In other words, social and potential freedom are part of a wider set of external conditions for happiness, while psychological freedom is about inner capability to deal with these conditions, which is not implied in these.

\subsection{Happiness and perceived freedom}

The strongest correlations in Table 7 are between happiness and perceived freedom in nations. The zero-order correlation is +.64 , which fits the earlier analysis of Verme (2009). The partial correlation is somewhat lower, but with +.48 still sizable.

\subsection{Paths from freedom to happiness}

So all kinds of freedom correlate more or less with average happiness in nations, since these variants of freedom are inter correlated (cf. Table 5) one kind of freedom may affect happiness through the other. Below we report some attempts to disentangle these effects.

\section{Simple path}

To what extent perceived freedom can be explained by actual freedom? We aggregate the z-scores of the three types of freedom and build an 'actual freedom' indicator, and calculate zero order correlations as well as partial correlations between actual freedom, perceived freedom and happiness. Results are presented in Figure 3 below. The link between actual freedom and happiness is the most important one. When controlling for actual freedom, the partial correlation between happiness and perceived freedom is much lower $(r=+.40)$ than the zero order correlation, but it still does not explain everything. One reason might be that there is an illusory freedom that does not find echo in the ground of actual freedom. Another reason may again be that the indicators of actual freedom do not cover all opportunity to choose Figure 2 .

\section{Full path}

As shown in the previous sections there are differences in actual freedom and in perceived freedom, and each correlate with happiness. Social freedom and potential represents the

Table 7 Actual and perceived freedom in France and in Finland, z scores range [0-1]

\begin{tabular}{llll}
\hline Freedom & France & Finland & Percentage of difference in scale range in rich nations \\
\hline Actual freedom & 0.47 & 0.78 & $31 \%$ \\
Social freedom & 0.62 & 0.74 & $12 \%$ \\
Psychological freedom & 0.37 & 0.68 & $31 \%$ \\
Potential freedom & 0.92 & 1 & $8 \%$ \\
Perceived freedom & 0.53 & 0.93 & $40 \%$ \\
\hline
\end{tabular}




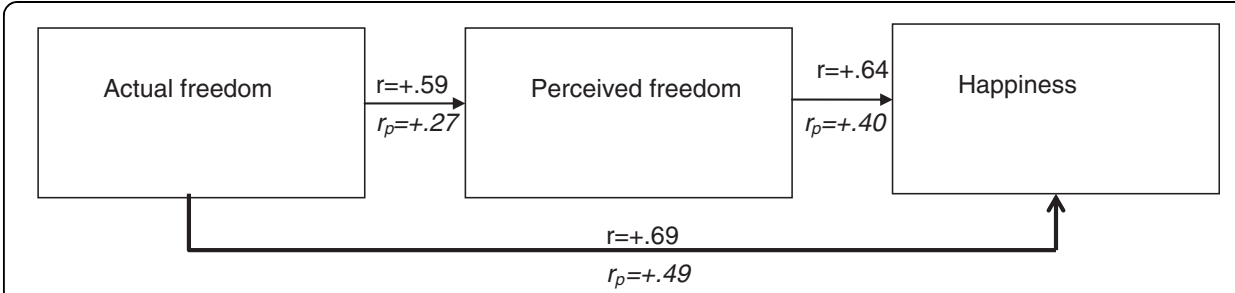

Figure 2 Link between actual freedom, perceived freedom and happiness in rich nations for the period 2000-2009 $(\mathrm{N}=40)$.

freedom of the environment in which individuals live; so we expect them to have a large influence on happiness, as largely depicted in the literature but not to be the main contributors of perceived freedom per se. Conversely, we expect perceived freedom to be more a mental construal than a result of the environment, hence we expect perceived freedom to be determined mainly by psychological freedom; therefore, the influence of psychological freedom on happiness should be mediated by perceived freedom. We expect 1) an influence of psychological freedom on happiness via perceived freedom and a direct effect, 2) a direct influence of social freedom on happiness, 3) a direct influence of potential freedom on happiness.

We checked this hypothesized path using AMOS 5.0. See Figure 3. This analysis suggests that the three types of freedom influence happiness equally $(+.50,+.49$ and +.51$)$. There is also a direct effect of psychological freedom on perceived freedom. The hypothesized model showed a good fit with the data: $\mathrm{X}^{2}(3)=3.52, \mathrm{NFI}=0.95, \mathrm{CFI}=0.97, \mathrm{RMSEA}=0.06$.

\subsection{The case of Finland and France}

How does this all fit the difference in happiness between Finland and France? Finland scores better on all aspects of freedom However, whereas the difference in social and potential freedom are not that dramatic, the differences in psychological freedom and perceived freedom are very strong, as shown in Table 7.

\section{Discussion}

\section{Explanations}

So much of the difference in average happiness between Finland and France seems to be in psychological freedom. This raises the question of what explains these disparities in psychological freedom. Socialization naturally comes to mind. Socialization is deeply

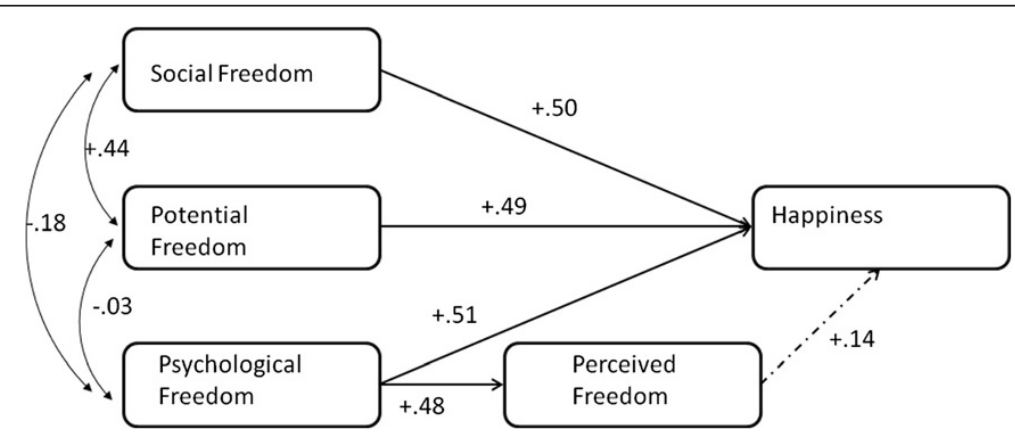

Figure 3 Happiness and freedom in nations 2000-2009; a path model. $C F I=0.95, R F I=0.97$, RMSEA $=0.06, \mathrm{~N}=33$. 
embedded in a culture and involves several aspects. The first is parental rearing. When asked about what are the important values to teach a child, French parents, for instance, tend to be keener to answer "obedience" than their Finnish counterparts, 35\% in France versus 28\% in Finland. Finnish parents tend to value much more "independence", 57\% in Finland versus $24 \%$ in France. We can imagine this has an influence on the psychological freedom for the inhabitants of rich countries.

A second explanation could be in education and we found a clue in teaching practices. Two kinds of teaching practices can be distinguished: horizontal teaching and vertical teaching (Algan et al. 2011). In horizontal teaching, children are encouraged to work in groups and self-motivate, in the vertical teaching lecturing and note taking is favoured. France has the most vertical teaching system whereas the Finnish system appears among the most horizontal ones. We can easily imagine that psychological freedom and feelings of freedom follow the same pattern and there is a link between teaching practices and happiness (Brulé \& Veenhoven, Teaching practices and happiness in nations, in preparation).

Another possible explanation for the disparity in psychological freedom is religion. Protestantism dominates in Finland and Catholicism in France. Several studies have shown that Catholicism tends to foster hierarchical relations. The church is hierarchical in itself with its many different levels, pope, bishops, priests, monks, etc., that is led from the top down and where there is little room for interpretation. Protestantism, in contrast, sees less need for intermediaries between the believer and God and leaves the believer more freedom. Thus, the Catholic's "top-down approach" will create less psychological freedom than the Protestant's "bottom-up approach". This viewpoint is explored in detail in Brulé and Veenhoven (2012).

\section{Limitations}

Cases

It should be noted that the number of nations used here is fairly limited, with just above thirty countries for which full data set is available. This analysis should be replicated once more data become available.

\section{Measurement}

The measurement of freedom in nations was not ideal either. Regarding social freedom, we were limited by the data available to build an indicator of personal freedom; a few indicators, especially the ones built by Humana (1992), were a grade from 1 to 4 . While this might be fine to compare all nations, this is not the best indicator when comparing developed nations, as most of them have the best grade. Likewise, the results from the World Values Survey cannot be used as they are based on surveys, and our intention was to avoid a response factor effect and use objective data (i.e., either data that is either measurable or drawn from experts ratings). Therefore, we were limited in the construction of some indicators, particularly for personal freedom. This also means we need more objective indicators of types of freedom such as contraception, homosexuality or euthanasia.

Regarding psychological freedom, we used acquiescence and low self-esteem as a proof to lack of guts. We see self-esteem as a prerequisite to take risks and seize opportunities, which 
is congruent with the definition of psychological freedom. Likewise, acquiescence, which according to Schmitt et al. (2007) is more present in the collectivistic cultures, obviously carries a cultural load and can be seen as a form of social code. Together with the social code, acquiescence carries a form of mental restrictions to answer bluntly. A way to complete this indicator would be to add a proper indicator of risk avoidance.

Finally, we feel our operationalization of potential freedom is decent. However, the way we defined these three types of freedom is just a first step. We certainly hope to see future improvement in the construction of these indicators.

\section{Causality}

This study reports a cross-sectional analysis and that method sets limits to identifying causality. Possibly part of the correlation is due to effects of happiness on freedom, rather than reversely and this is most likely to be the case with psychological freedom. Trend analysis can answer that question when more data points become available in the future,

\section{Conclusion}

Much of the difference in average happiness across rich nations is due to variation in freedom, not only perceived freedom, but independent of that also actual freedom and in particular psychological freedom. The Finns are happier than the French because they feel more free and are more free and their greater actual freedom is not only a matter of less restrictiveness in Finish society but also of greater guts to be free.

\section{Endnote}

${ }^{a}$ Rich nations are shown in Figure 1. 49 nations are included in this group: Argentina, Australia, Austria, Bahamas, Bahrain, Barbados, Belgium, Brunei, Canada, Croatia, Cyprus, Czech Republic, Denmark, Estonia, Finland, France, Germany, Greece, Guinea, Hong-Kong, Hungary, Iceland, Israel, Italy, Japan, Korea, Kuwait, Luxemburg, Malta, Netherlands, New Zealand, Norway, Oman, Poland, Portugal, Puerto Rico, Qatar, Saudi Arabia, Seychelles, Singapore, Slovak Republic, Slovenia, Spain, Sweden, Switzerland, United Arab Emirates, United Kingdom, United States.

Competing interests

The authors declare that they have no competing interests.

\section{Authors' contributions}

GB and RV discussed the link between objective freedom, subjective freedom and happiness and agreed on a methodology. GB did the modelling and wrote the report reviewed by RV. GB and RV read and approved the final manuscript.

\section{Acknowledgements}

The authors would like to thank Miranda Aldham-Breary for her English editing.

\section{Author details}

${ }^{1}$ Erasmus University Rotterdam, Rotterdam, Netherlands. ${ }^{2}$ Erasmus Happiness Economics Research Organization, POB

1738, NL3000DR Rotterdam, Netherlands. ${ }^{3}$ North-West University, South Africa.

Received: 21 March 2014 Accepted: 14 August 2014

Published online: 25 September 2014

\section{References}

Algan, Y, Cahuc, P, \& Shleifer, A. (2011). Teaching practices and social capital (Discussion Paper series). Forschungsinstitut zur Zukunft der Arbeit, No. 6052,http://nbn-resolving.de/urn:nbn:de:101:1-201111029385.

Bay, C. (1970). The structure of freedom. Stanford: Stanford Univ Pr.

Brulé, G, \& Veenhoven, R. (2012). Why are Latin Europeans less happy? In The impact of hierarchy. Polyphonic Anthropology Theoretical and Empirical Cross-Cultural Fieldwork. Rijeka: InTech. 979-953-307-388-9. 
Cantril, H. (1965). The pattern of human concerns. New Brunswick, NJ: Rutgers U. P.

Freedom House F. (2005). Freedom in the World 2005: civic power and electoral politics. New York: Freedom House.

Gallup, G. (2009). Guide to public opinion polls. Washington, D. C: Gallup.

Gwartney, JD, \& Lawson, R. (2006). Economic freedom of the world. Vancouver, BC: The Fraser Institute. Data retrieved from www.freetheworld.com.

Humana, C. (1992). World Human Rights Guide. New York: Oxford University Press.

Messick, RE, \& Kimura, K. (1996). World survey of economic freedom 1995-1996: a Freedom House study. New Brunswick, N.J. Transaction Publishers.

Ott, JC. (2010). Good governance and happiness in nations: Technical quality precedes democracy and quality beats size. $J$ Happiness Stud, 11, 353-368

Rosenberg, M. (1965). The measurement of self-esteem. In Society and the adolescent self -image (pp. 16-36).

Schmitt, DP, \& Allik, J. (2005). Simultaneous Administration of the Rosenberg Self-Esteem Scale in 53 Nations: Exploring the Universal and Culture-Specific Features of Global Self-Esteem. J Pers Soc Psychol, 89(4), 623-642.

Schmitt, DP, Allik, J, McCrae, RR, \& Benet-Martinez, V. (2007). The geographic distribution of big five personality traits: Patterns and Profiles of Human Self-Description Across 56 Nations. J Cross-Cult Psychol, 38, 173.

Smith, PB. (2004). Acquiescent Response Bias as an Aspect of Cultural Communication Style. J Cross-Cult Psychol, 35, 50 United Nations-United Development Reports. (1998). United Nations Development Program. New York USA: Oxford University Press. http://hdr.undp.org/en/.

United Nations-United Development Reports. (2007). United Nations Development Program. New York USA: Oxford University Press. http:/hdr.undp.org/en/.

Veenhoven, R. (1984). Data-book of happiness. Dordrecht: Springer.

Veenhoven, R. (2000). Freedom and happiness: A comparative study in forty-four nations in the early 1990s. In Culture and subjective well-being (pp. 257-288).

Veenhoven, R. (2009). 3. How do we assess how happy we are? Tenets, implications and tenability of three theories. In Happiness, economics and politics: towards a multi-disciplinary approach (Vol. 45). Northampton MA: Edward Edgar Pub.

Veenhoven, R. (2011). States of Nations Data set to be used for the cross-national analysis of happiness. Rottodam: Erasmus University.

Veenhoven, R. (2014a). Measures of happiness. In World Database of happiness. Rotterdam: Erasmus University. Accessed on 1-11-2011 at worlddatababaseofhappiness.eur.nl/hap_quer/hqi_fp.php.

Veenhoven, R. (2014b). Happiness in Nations. In World Database of Happiness. Rotterdam: Erasmus University. Accessed on 12/08/11 at: worlddatababaseofhappiness.eur.nl/hap_nat/nat_fp.php

Verme, P. (2009). Happiness, freedom and control. J Econ Behav Organ, 71, 146-161.

World Values Survey. worldvaluessurvey.org

doi:10.1186/s13612-014-0017-4

Cite this article as: Brule and Veenhoven: Freedom and happiness in nations: why the Finns are happier than the French. Psychology of Well-Being: Theory, Research and Practice 2014 4:17.

\section{Submit your manuscript to a SpringerOpen ${ }^{\circ}$ journal and benefit from:}

- Convenient online submission

- Rigorous peer review

- Immediate publication on acceptance

- Open access: articles freely available online

- High visibility within the field

- Retaining the copyright to your article

Submit your next manuscript at $\boldsymbol{\sim}$ springeropen.com 